TP Periodica Polytechnica Civil Engineering

\author{
62(2), pp. 508-516, 2018 \\ https://doi.org/10.3311/PPci.11411 \\ Creative Commons Attribution (i)
}

RESEARCH ARTICLE

\section{Properties of Portland Cement Mortar with Substitutions of Natural and Expanded Perlite}

Mauricio Arreola Sánchez ${ }^{1}$, Wilfrido Martínez Molina ${ }^{1}$, Hugo Luis Chávez García ${ }^{1 *}$, Elia Mercedes Alonso Guzmán ${ }^{1}$, Andrés A. Torres Acosta ${ }^{2}$ and José María Ponce Ortega ${ }^{3}$

Received 22 August 2017; Revised 03 October 2017; Accepted 18 December 2017

\begin{abstract}
The present research deals with the feasibility of using hightemperature pozzolans such as Natural Perlite (NP) and Expanded Perlite (EP), different dosagues of additions were made to mortars in order to perform their mechanical properties. Mortars were subjected to destructive tests in hardened state: compression, tension, flexion and adhesion strength; as well as non-destructive tests in hardened state: ultrasonic pulse velocity (UPV), electrical resistivity (ER), density ( $\rho)$ and total porosity (PT); in addition to attack by sodium sulfate at 90 days. The percentages of the substitutions were $5 \%$, $10 \%, 15 \%, 20 \%$ and $30 \%$ by weight of Portland cement mass $(P C)$ relative to a control mortar (cement-sand-water). With the partial replacement of the cement and according to the tests carried out, it can be observed that the problem of durability and $\mathrm{CO}_{2}$ emissions is significantly reduced and, consequently, an energy saving and a lower environmental impact are promoted.
\end{abstract}

\section{Keywords}

cement mortar, natural perlite, expanded perlite, pozzolan

\section{Introduction}

In the last decades, the importance of the durability of hydraulic concrete and mortar has been increasing, since the behavior that throughout the useful life have presented the structures designed only under the criteria of mechanical resistance has not been adequate enough, in places where there are aggressive atmospheres for the works $[1,2]$.

For the above, it has been proven that, in order to achieve a reinforced concrete structure to cover its useful life in optimal conditions of service, it is indispensable to consider, besides a good design by resistance, a design for durability appropriate to the atmospheric conditions where will build [3].

One way to prevent the action of the mechanisms which diminish the durability of the elements elaborated with cement is the use of pozzolans as partial substitutes of the cement [4]. Pozzolans are materials that when added to concrete and/or mortar tend to improve their physical-mechanical and durability characteristics, for example, Natural Perlite (NP) and Expanded Perlite (EP) inhibit the alkali-silica reaction, being more efficient EP than NP [5].

EP is worldwide used material. Due to its low bulk density is used mainly in building materials technology (as a filler in lightweight composites, thermal, acoustic, fire insulation) [4] as well as in horticulture and agriculture.

Pozzolans were widely used in antiquity, before the invention of cement, and it has now been shown in several studies that pozzolans of organic origin can achieve a better performance of concrete [3].

Among supplementary cementitious materials (SCMs) used in cement and concrete industry there are fly ashes [6], ground granulated blast furnace slag, calcined clays [7], as well as limestone, natural zeolites [8] and limestone [9]. Use of SCMs leads to reduce the content of Portland clinker in cement and what is connected, reduces the total amount of $\mathrm{CO}_{2}$ released [10].

In addition, the use of pozzolanic materials reduces the amount of waste deposited in the environment, since many of the byproducts derived from agro industrial and industrial processes are ashes and residues with high pozzolanic potential. Therefore, the use of these materials as substitutes for cement 
results in an ecological and environment-friendly material and low impact, coupled with the improvement of its physical-mechanical properties and durability [11].

Perlite is a natural pozzolan abundant in several countries which are major producers of cement. This makes perlite attractive for producing sustainable concretes [12] and is an amorphous form of rhyolitic or dacitic magma that contains $2-5 \%$ water [13].

Mielenz et al. [14] wrote "When selected, processed, and properly used, pozzolans can reduce costs, improve the quality of concrete, protect concrete against reactions of aggregate and cement alkalis, and inhibit attack by aggressive waters. "

It is important to know the chemical characteristics of the pozzolans that will be used and the reactivity that will have with the cement since these can have variations. In addition, it is difficult to find in the literature the behavior of pozzolans from different regions, particular case is perlite [12].

In several investigations made with NP, ground perlite and waste expanded perlite (WEP) in partial substitution of cement and mortar mixtures, it has been demonstrated that the normal consistency is similar to the control mixture, in addition the mortar mixtures have low permeability to early ages, therefore it has better resistance to the inclemency; And low compressive strength at ages of 91 days, compared to the control mixture $[15,16,17,18]$.

In this research, mortar mixtures with partial cement substitutions were prepared by NP and PE in 5 different percentages, in order to improve the mechanical properties and durability of the mixtures, for which destructive mechanical tests and nondestructive tests were carried out as well as durability tests, comparing the results obtained with a control mixture to indicate the best substitution used.

\section{Experimentation}

\subsection{Materials}

The cement used was CPC 30R RS, according to the Mexican standard NMX C 414-2010 [19], is equivalent to Type II cement as ASTM C150 [20].

An arid with a high content of quartz was used, which was screened by meshes $\mathrm{N}^{\circ} 16$ and $\mathrm{N}^{\circ} 30$ being used only the material between both meshes, in order to comply with the characteristics indicated in the standard ASTM C 91 [21].

\subsection{Design of blends}

The experimentation was divided into three stages; in the first stage a characterization of the materials to be used was carried out; in the second stage it was determined which percentages of substitution of each material showed better mechanical behavior; and in the third stage the characterization of mechanical properties (compression, bending and tension) and physical properties (porosity, density, durability) was carried out, analyzing which improved the material under study.

\section{First stage}

The substitutions were analyzed only in the cement-water paste, in order to determine the normal consistency and the set times of the different substitute materials. The percentages of substitution of both natural perlite and expanded perlite were $5,10,15,20$ and $30 \%$ by weight of PC mass.

The test of setting times was performed using the Gilmore method, according to ASTM C 266-15 [22].

Standard test method for the normal consistency of hydraulic cement was performed according to ASTM-C-187-16 [23].

\section{Second stage}

Based on the results obtained in the first stage the design of the mixtures to be made was determined, the design is shown in Table 1.

Table 1 Employees percentage for mixtures

\begin{tabular}{lcccccc}
\hline \multirow{2}{*}{ Material } & \multicolumn{6}{c}{ Substitutions for EP, NP } \\
& $0 \%$ & $5 \%$ & $10 \%$ & $15 \%$ & $20 \%$ & $30 \%$ \\
\hline Cement & 100 & 95 & 90 & 85 & 80 & 70 \\
Substitute Material & 0 & 5 & 10 & 15 & 20 & 30 \\
Water/cementitious Relation & 1.01 & 1.01 & 1.01 & 1.01 & 1.01 & 1.01 \\
Sand/cementitious Relation & 2.75 & 2.75 & 2.75 & 2.75 & 2.75 & 2.75 \\
\hline
\end{tabular}

The water/cement ratio was set at $1.01[24,25,26]$, which was necessary for the control mixture to comply with the flow according to ASTM C 1437-15 [27].

When the w/c ratio did not meet the fluidity of $110 \pm 5 \mathrm{a}$ fluidifier was added (manufacturer recommends the following dosage: one bag of $200 \mathrm{~g}$ of product per each bag of $50 \mathrm{~kg}$ ) [28]; the manufacturer recommends the following dosage: One bag of $200 \mathrm{~g}$ of product per each bag of $50 \mathrm{~kg}$.

The fluidifier was used only in those blends that did not comply with the workability. The different tests to be performed in the experimentation are detailed in the following subchapter.

\section{Third stage}

\section{Particle shape}

The SEM technique was used to determine the particle shape. The samples were analyzed by Semi-quantitative X-ray Fluorescence Spectrometry (FRX) with wavelength dispersion, using a BRUKER Model S4 PIONEER equipment, which is equipped with a $4 \mathrm{~kW}$ excitation source, the Interpretation of the data was performed using the SPECTRA plus software. Compressive strength and pozzolanic activity index (PAI).

The procedure of ASTM C 109 / C 109M [29] was followed for analysis of the axial load strength of the hardened mixtures. Which specifies the elaboration of cubes of $5 \mathrm{~cm}$ per side. Three specimens were prepared for each test age and for each mixture, cubes were prepared for the test ages of 14, 28, 45, 90, 180 and 360 days.

With the compressive strength test of the mortars, it is also possible to determine if the substitute materials show 
any indication of reaction with the reaction products of the cement (calcium hydroxide), this is achieved by calculating the Resistive Activity Index or RAI. According to ASTM C 31116 [30], there are two ways of calculating this index, the first is through a chemical analysis and the second is through a tax analysis. The method used in this investigation was the second one, which relates the compressive strength of the control mortar with the resistance of the mortar made with the substitute materials.

\section{Resistance to bending}

To determine the flexural strength of the mortars, $40 \mathrm{~mm} \times 40$ $\mathrm{mm} \times 160 \mathrm{~mm}$ specimens were prepared from prisms according to ASTM C 348-14 [31]. Just as the cubes were elaborated are prisms for the test ages of 14, 28, 45, 90, 180 and 360 days.

\section{Resistance to tension}

To determine the tensile strength of mortars, briquettes (peanut specimens) were made with the corresponding mixtures and substitutions [32].

The filling of the briquettes consists of filling the molds by compressing the mixture with the index finger and raising it with the aid of a spatula, since the molds do not have a base in which the mixture will remain, the mold is placed on a glass surface, Greased in advance to prevent the mixture from adhering to it. The specified test ages of 14, 28, 45, 90, 180 and 360 days. The calculation was performed using Eq. (1).

$$
R A=(P m \times 50) / S m
$$

Where: $P m$ is the load recorded in $\mathrm{kg}$ and $\mathrm{Sm}$ is the median section of the specimen in $\mathrm{cm}^{2}$.

\section{Resistance to sulfate attack}

For the analyses of resistance to attack by sulfates, cubic specimens of $50 \mathrm{~mm}$ per side were made, these specimens were made in the same way as the cubes for the test of resistance to compression, only that in this case 18 cubes were made for each percentage of substitution.

The specimens were subjected to attack by sodium sulfate at the age of 90 days, the procedure of the attack test was in accordance with the ASTM C 88 standard [33], which recommended that the solution for attack specimens contains not less than $350 \mathrm{~g}$ of anhydrous sodium sulphate salt and that the attack is by immersion cycles in salt.

The solution was done $18 \mathrm{hrs}$ before the test, prior to the first dipping the specimens must be dried until constant weight and then oven drying at $110 \pm 5^{\circ} \mathrm{C}$; so on until the completion of the required cycles.

For this test 5 cycles were performed on each mortar mixture, the weights of the specimens were recorded at the end of each cycle and also at the end of each cycle 3 specimens were tested at axial load registered their loss of both mass and resistance.

For the specimens tested at axial load, their electrical resistivity and pulse velocity were also measured to analyze their behavior against sulfate attack.

\section{Resistance to adherence}

The adherence test was carried out according to ASTM C 1583 [34], concrete slabs of $1 \mathrm{~m} \times 1 \mathrm{~m} \times 0.07 \mathrm{~m}$ were made, in order to perform the adhesion test on them. The concrete slabs were $200 \mathrm{~kg} / \mathrm{cm}^{2}$, with gravel volcanic stone material and cement type II ASTM C150. To perform the adherence test, small stainless steel discs were used; these are adhered to the surface of the slabs by means of an epoxy and then allowed to dry between 3-4 hrs. These discs have a perforation in which the test equipment is secured to apply an axial load in the opposite direction to the test surface. The adhesion test was performed at the ages of 14, 28, 45, 90 and 180 days.

\section{Electrical resistivity}

The electrical resistivity of the concrete or mortar is related to the microstructure of the cement matrix, its pore structure, porosity and pore size distribution. It is also a function of ion concentration and its mobility in the pore solution [35]. The chemistry of cement, cement content, water/cement ratio and the use of additives and supplementary cementitious materials are factors that influence the microstructure of the cement matrix, as well as the chemistry of the pore solution, and therefore influence their electrical resistivity [36].

Measurements corresponding to this test were made with a resistor equipment that measures electrical resistivity in soils and porous materials. The electrical resistivity is given by Eq. (2).

$$
\rho=\operatorname{Re}(A / L)
$$

Where; $\rho$ is the electrical resistivity in $\mathrm{K} \Omega-\mathrm{cm}$ (ohm-m), Re is the electrical resistance that the equipment provides in $\mathrm{K} \Omega$, A is the cross-sectional area of the specimen in $\mathrm{cm}^{2}$ and $L$ is the length of the specimen in $\mathrm{cm}$.

\section{Results}

\subsection{Particle shape}

In Figure 1, it can be seen that the particle shape of the NP is angular, similar to that of Portland cement, but only of a larger size.

Figure 2 shows the particle shape of the EP, a hollow spherical shape of the EP particles is observed, which is due to the effect of the heating and migration of the water contained in the mineral perlite, also a size of particle much larger than that of Portland cement used but thinner.

Chemical composition of study materials (NP and EP) are shown Tables 2 and 3 show the amount of aluminum and silicon oxides, with which it is possible to determine if the materials are potentially pozzolanic. For the case of both materials, NP and EP are classified as a class F pozzolan [37]. 


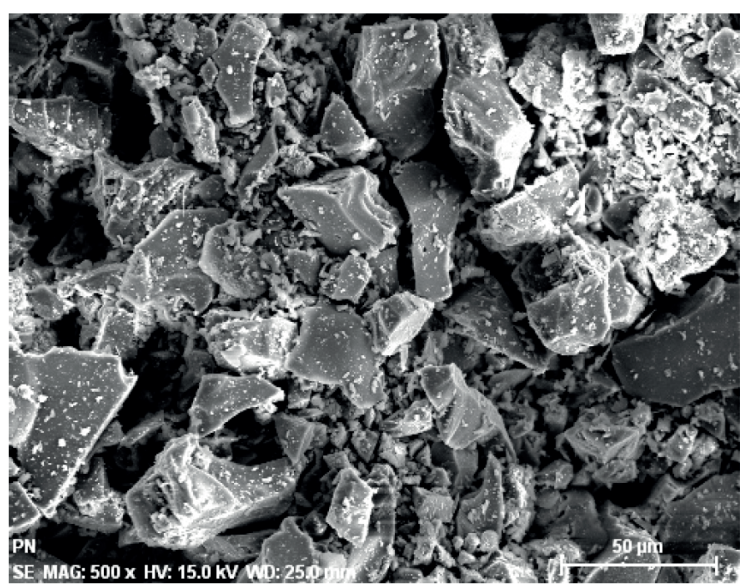

(a)

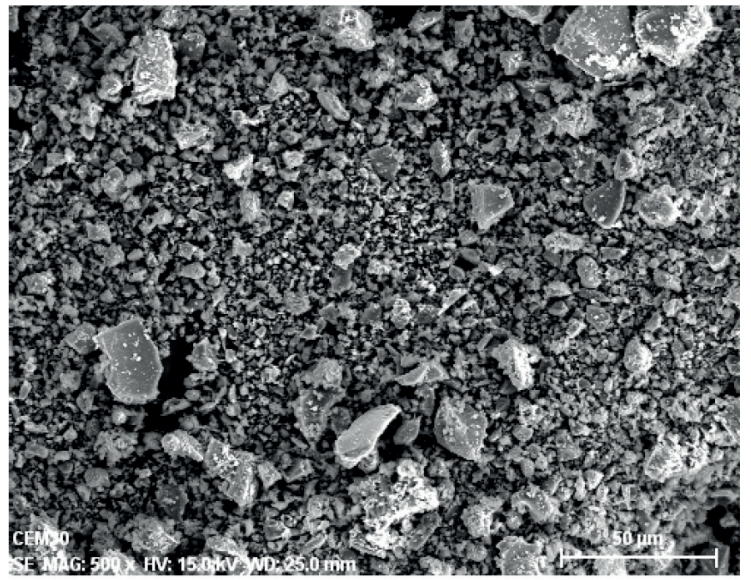

(b)

Fig. 1 a) NP particle shape, b) and cement CPC 30R RS

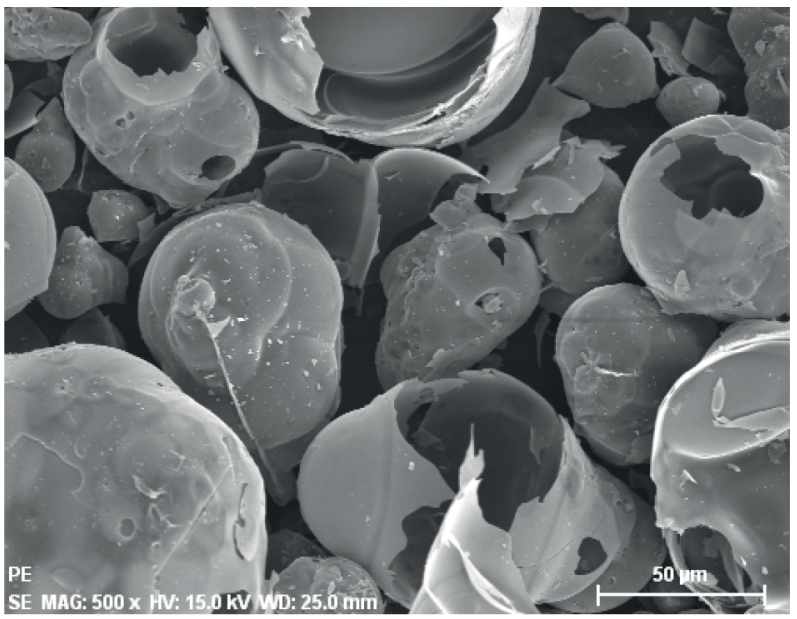

Fig. 2 Particle shape of EP

Table 2 Chemical composition of the NP

\begin{tabular}{lllc}
\hline Component & \multicolumn{1}{c}{$\%$} & Component & $\%$ \\
\hline $\mathrm{SiO}_{2}$ & 72.197 & $\mathrm{CaO}$ & 1.052 \\
$\mathrm{Al}_{2} \mathrm{O}_{3}$ & 0.115 & $\mathrm{Na}_{2} \mathrm{O}$ & 3.216 \\
$\mathrm{TiO}_{2}$ & 13.58 & $\mathrm{~K}_{2} \mathrm{O}$ & 4.285 \\
$\mathrm{Fe}_{2} \mathrm{O}_{3}$ & 1.011 & $\mathrm{PXC} / \mathrm{PPI}$ & 3.99 \\
$\mathrm{MgO}$ & 0.538 & $\mathrm{BaO}$ & 0.000 \\
$\mathrm{MnO}$ & 0.073 & $\mathrm{P}_{2} \mathrm{O}_{5}$ & 0.025 \\
\hline & & & Sum $=100.082$ \\
\hline
\end{tabular}

Table 3 Chemical composition of the EP

\begin{tabular}{lclc}
\hline Component & $\%$ & Component & $\%$ \\
\hline $\mathrm{SiO}_{2}$ & 73.591 & $\mathrm{CaO}$ & 1.333 \\
$\mathrm{Al}_{2} \mathrm{O}_{3}$ & 0.13 & $\mathrm{Na}_{2} \mathrm{O}$ & 2.918 \\
$\mathrm{TiO}_{2}$ & 13.426 & $\mathrm{~K}_{2} \mathrm{O}$ & 5.013 \\
$\mathrm{Fe}_{2} \mathrm{O}_{3}$ & 1.166 & $\mathrm{PXC} / \mathrm{PPI}$ & 1.18 \\
$\mathrm{MgO}$ & 0.197 & $\mathrm{BaO}$ & 0 \\
$\mathrm{MnO}$ & 0.045 & $\mathrm{P}_{2} \mathrm{O}_{5}$ & 0.02 \\
\hline
\end{tabular}

\section{Compressive strength in samples with NP}

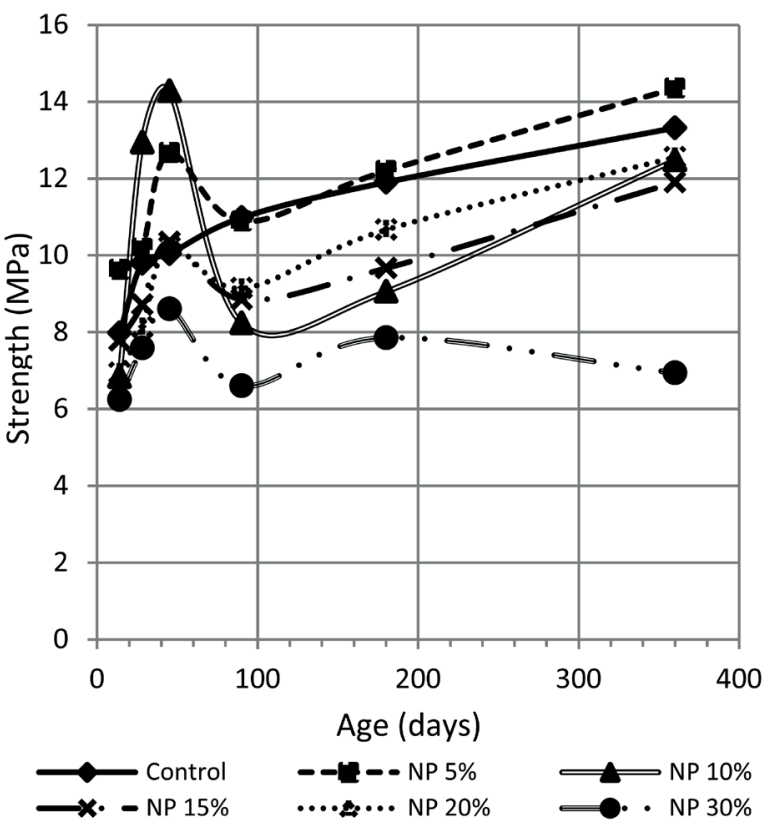

(a)

\section{Compressive strength in samples with EP}

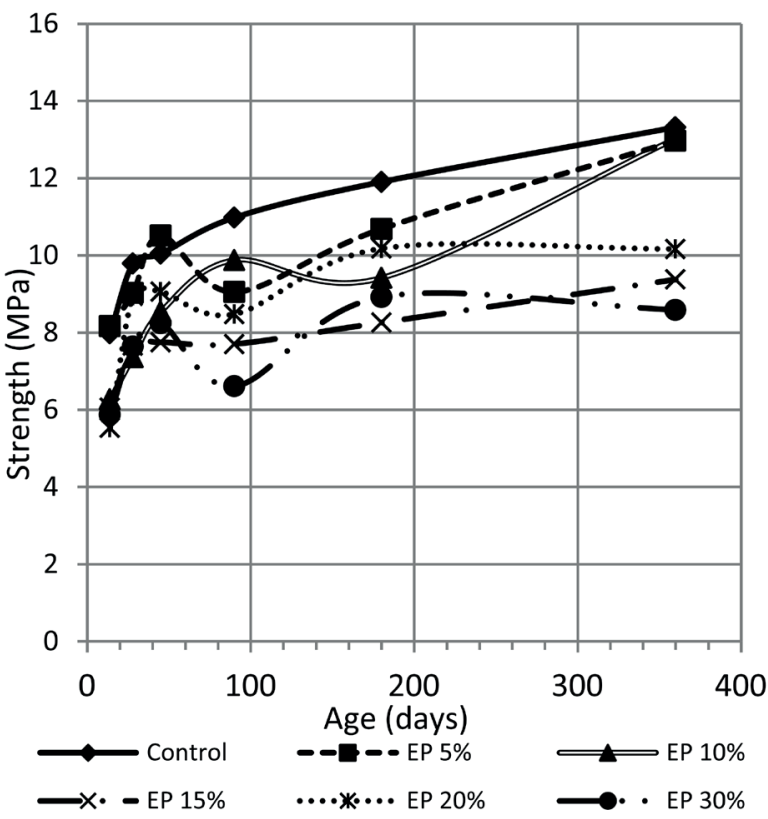

(b)

Fig. 3 a) Compressive strength of the Natural Perlite in its different percentages of substitution, b) compressive strength of the Expanded Perlite in its different percentages of substitution 
Figure 3a) shows the compressive strength results of NP; only $5 \%$ of substitution mixture was able to develop a slightly superior compressive strength than the control, which it is most notorious at the age of 360 days. The results of EP are shown in Figure $3 b$ ). It is observed that no substitution percentage can reach the mechanical performance of the control; only for EP 5 and 10\%, showed upward trend at 360 days age. This performance is attributable to the size of the particles of both materials, since, although it has a high content of aluminosilicates, the particle size is considerably larger than the cement used which impacts on the reaction rate of NP and EP.

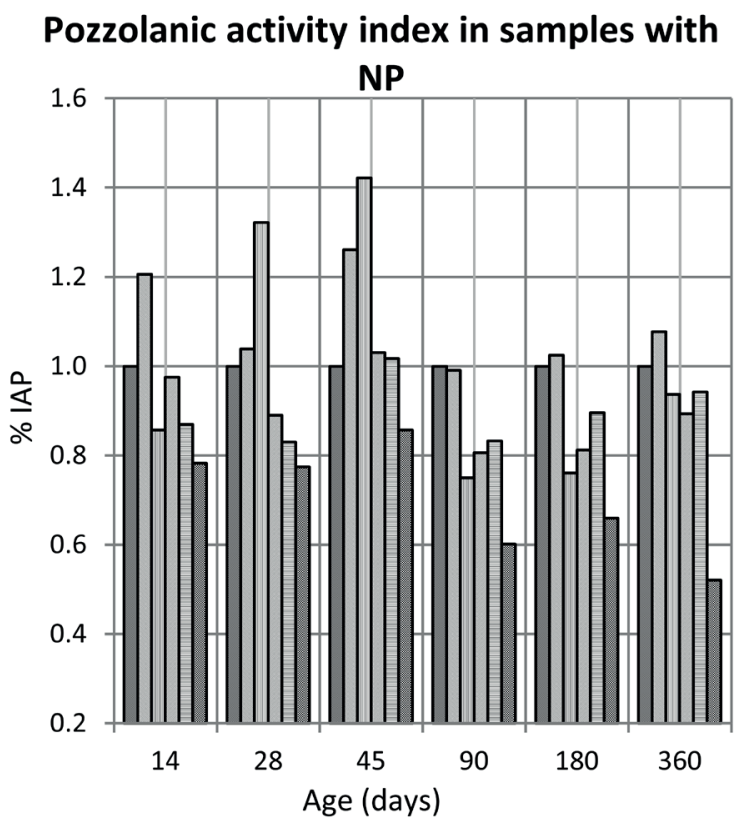

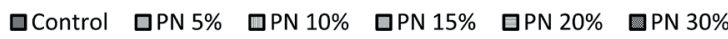

(a)

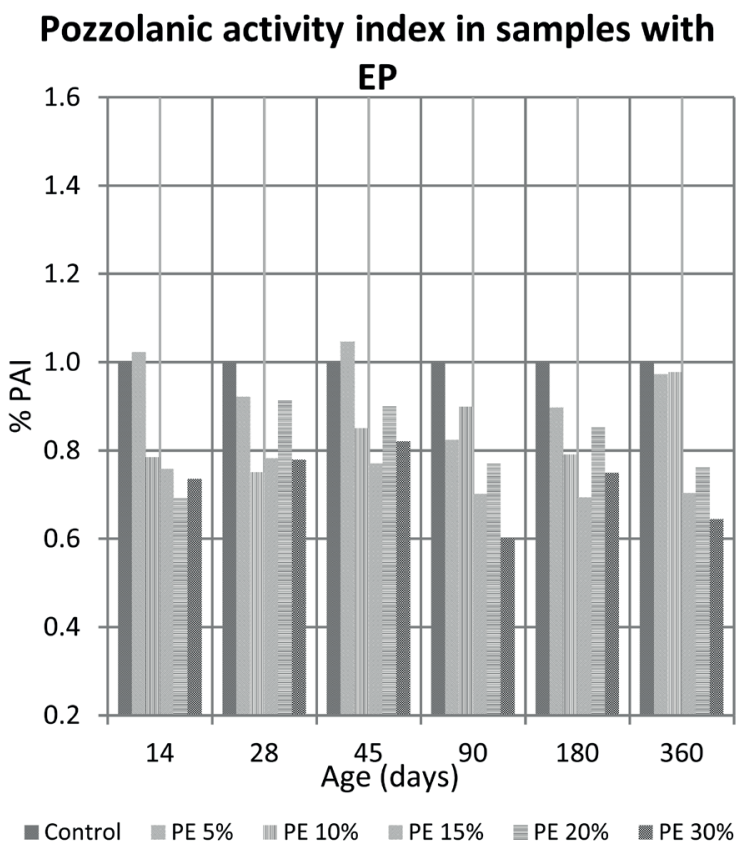

(b)

Fig. 4 a) Puzzolanic activity Index obtained from the physical analysis for NP, b) Puzzolanic activity Index obtained from the physical analysis for EP
Figure 4a) shows the PAI results obtained for NP, showing a better performance over time with $5 \%$ substitution and $10 \%$, being the best at 360 days age. A similar performance occurs in the EP, Figure 4b).

Bending strength results of the mixtures evaluated are shown in Figure 5. In figure 5a) it can be observed that the best results obtained correspond to $15 \%$ NP substitution at 360 days age, whereas in figure $5 \mathrm{~b}$ ) the best results are presented in 5\% EP substitution. For NP case, the performance differs from those shown in the compressive strength (best performance obtained was for 5\% NP substitution), since in flexure, the best performance for $10 \%$ and $15 \%$ NP substitutions, This can be attributed to a preferential accommodation of the NP particles, which increases their flexural strength.

\section{Modulus of rupture in samples with NP}

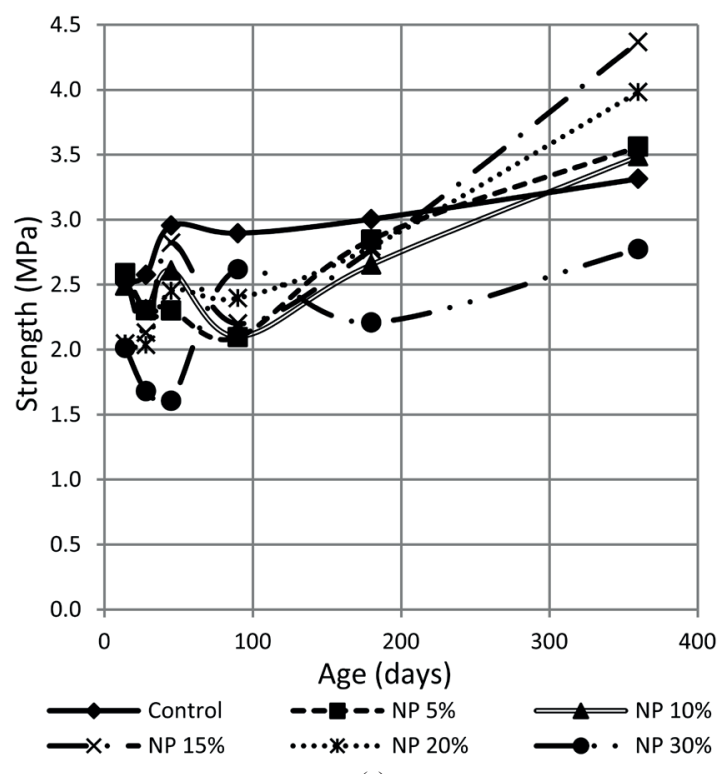

(a)

\section{Modulus of rupture in samples with EP}

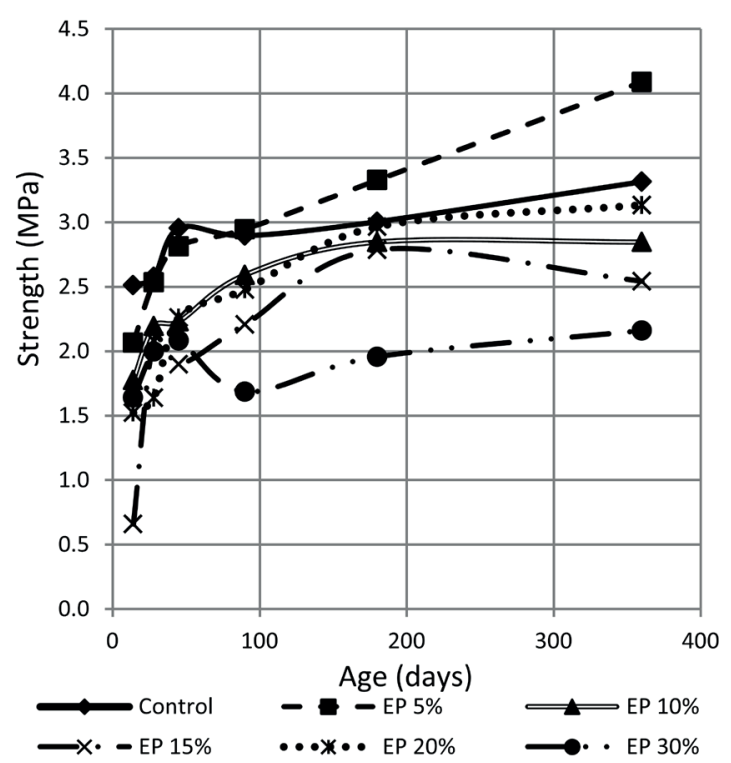

(b)

Fig. 5 a) Flexural strength of Natural Perlite in its different percentages of substitution, b) flexural strength of Expanded Perlite in its different percentages of substitution 
Figure 6 shows the tensile strength performance of the mixtures evaluated. For both NP (figure 6a), and for EP, figure 6b). As observed, the strength has an upward trend with respect to time. However, it is possible to observe a greater dispersion in EP results. The best results were reached with $20 \%$ NP substitution and $15 \%$ EP substitution, both quantified at 360 days age.

\section{Tensile strenght in samples with NP}

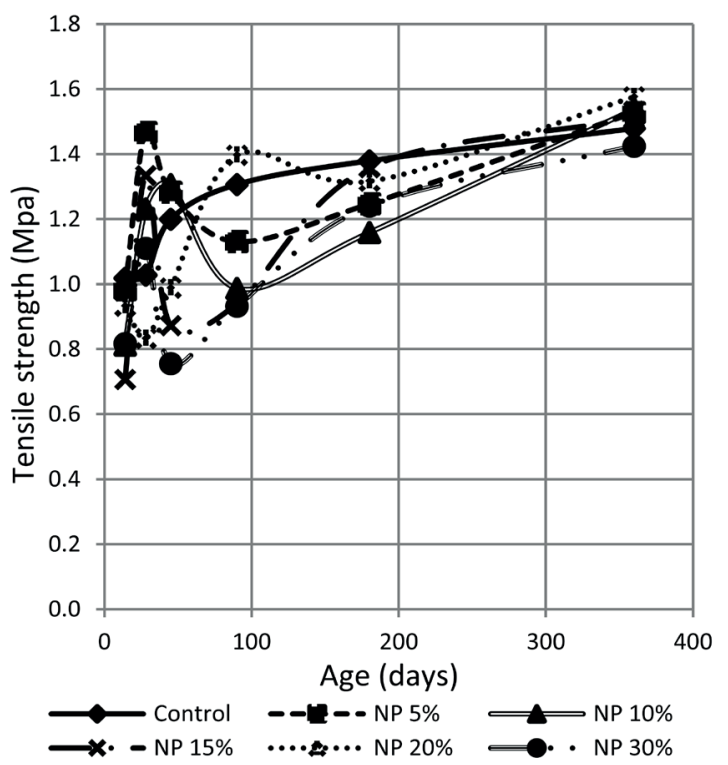

(a)

\section{Tensile strenght in samples with EP}

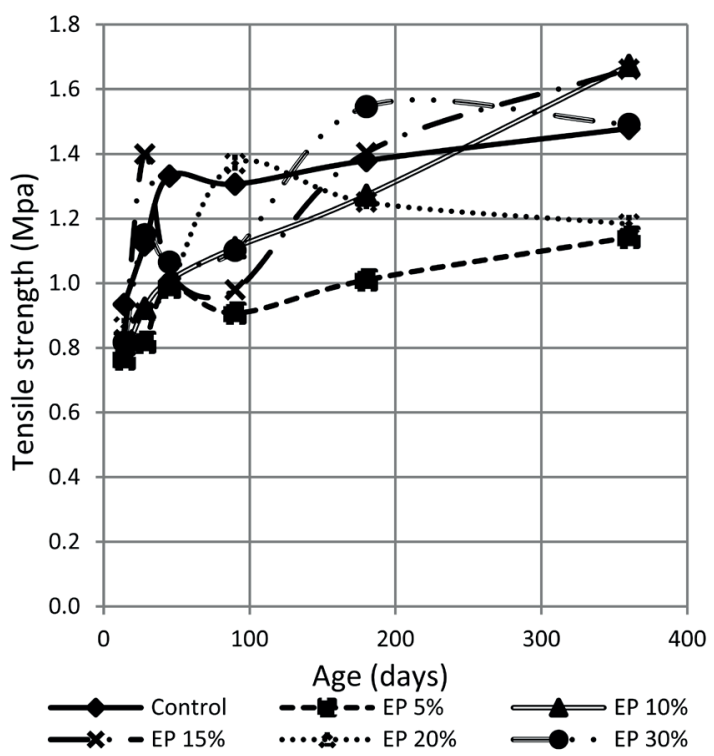

(b)

Fig. 6 a) Tensile strength in samples with Natural Perlite, b) tensile strength in samples of Expanded Perlite

Sulfate attack results obtained for the mixtures evaluated, are shown in figures $7 \mathrm{a}$ and $7 \mathrm{~b}$. Sulfate attack test allows us to measure the durability and/or stability of a material in contact with chemical agents. For the present study, the test was performed at the age of 90 days age. The samples were subjected to sulfate etching cycles and then to axial loading. In the case of NP, figure 7a), the mixture that showed a better performance was NP 5\% substitution, although, it failed to overcome the control mixture. Only the control mixture reached the quite sulfate attack cycle. In the case of EP mixtures (figure 7b), the percentages substitution that showed the best mechanical behavior before for attack by sulfates were $5 \%$, the mixtures with EP reached until the fourth cycle but with less resistance than to the control had. This performance is consistent with the compressive strength results, since also the mixtures with 5\% NP substitution present a similar performance than the control. As obtained in the mechanical performance of such mixtures, these results were due to, apparently, the low reactivity of the substituting materials.

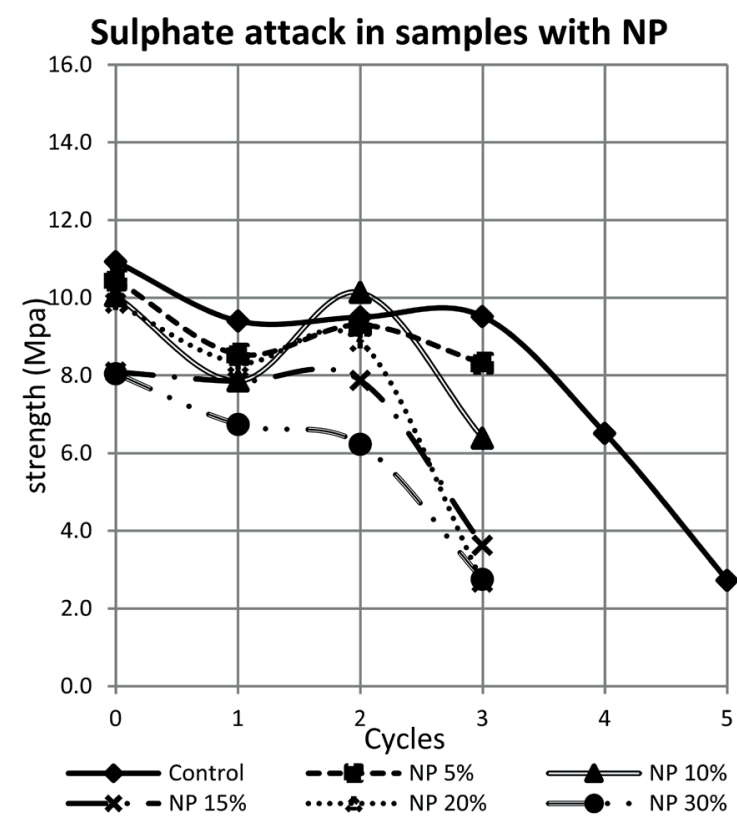

(a)

\section{Sulphate attack in samples with EP}

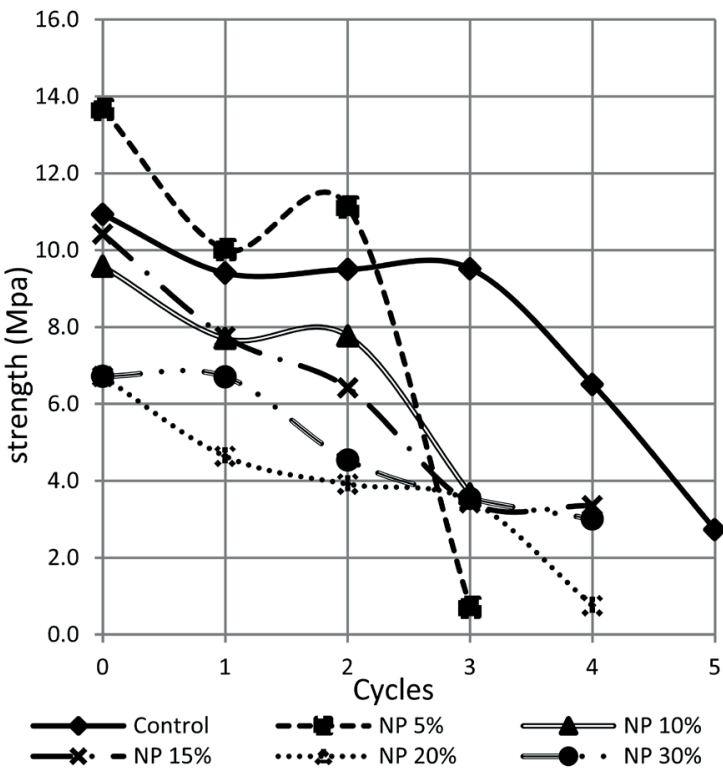

(b)

Fig. 7 a) Compressive strength of NP blends under sulfate attack, b) compressive strength of EP blends under sulfate attack 
Figure $8 \mathrm{a}$ ) and $8 \mathrm{~b}$ ) shows the bond strength results for NP and EP mixtures, respectively. Both mixtures show similar performance between if, being only the percentages of EP $5 \%$, NP $10 \%$ and NP $30 \%$, which present practically the same effort as the control at the age of 180 days, the tendency is upwards with respect to time.

\section{Adherence in samples with NP}

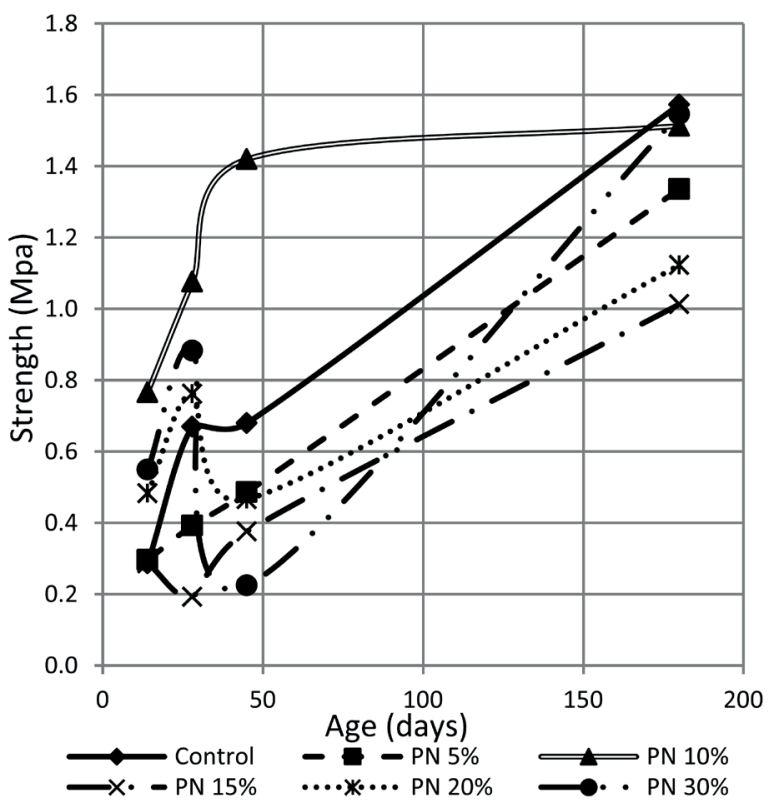

(a)

\section{Adherence in samples with EP}

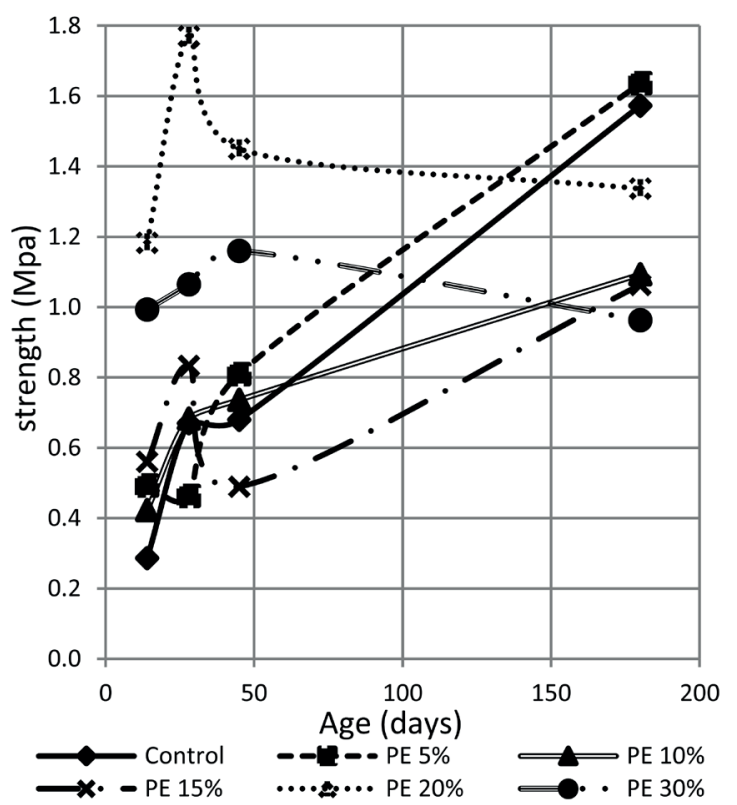

(b)

Fig. 8 a) Bond strength NP mixtures, b) bond strength for EP mixtures

In Figure 9a) and 9b), NP and EP mixtures electrical resistitvity results, respectively, are presented. Both show a higher value than the control, being NP mixtures the one that presented larger resistivities than EP mixtures. For the case of
NP substitution mixtures, all values exceed the control ones, with 20 and $30 \%$ of substitutions the ones with the highest of all. It also happened with the PE, only that in this case the $30 \%$ EP substitution presented a strong decrease at 360 days age. These results differ from the mechanical performance and sulfate attack resistance results obtained: resistivities superior to the control in both materials are observed. This could be attributed to a micro pore filled out, although that micro filled out does not reflect improvements in the sulfate attack test.

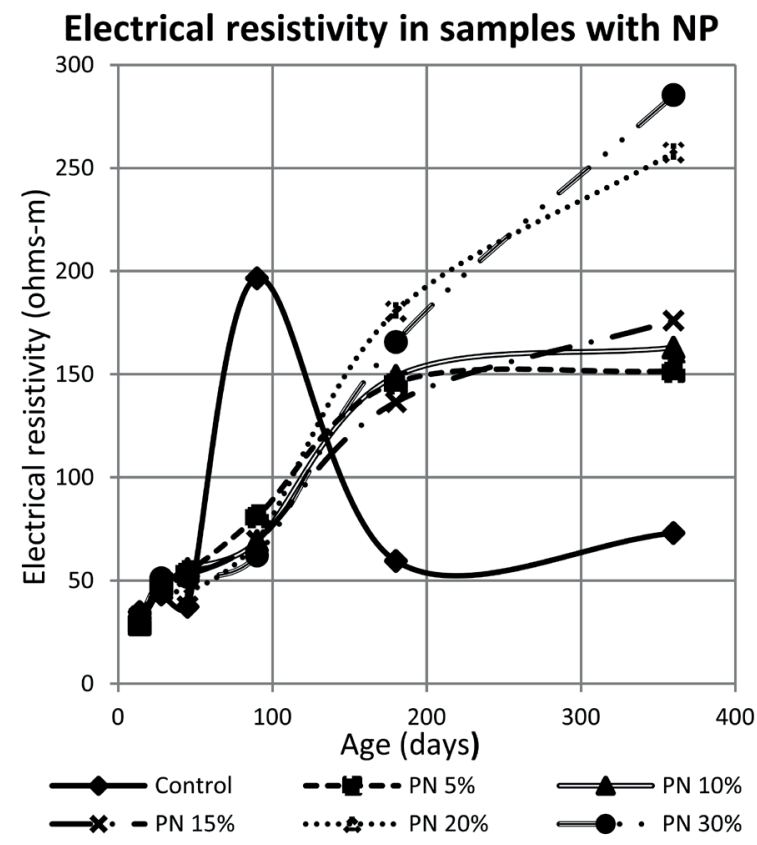

(a)

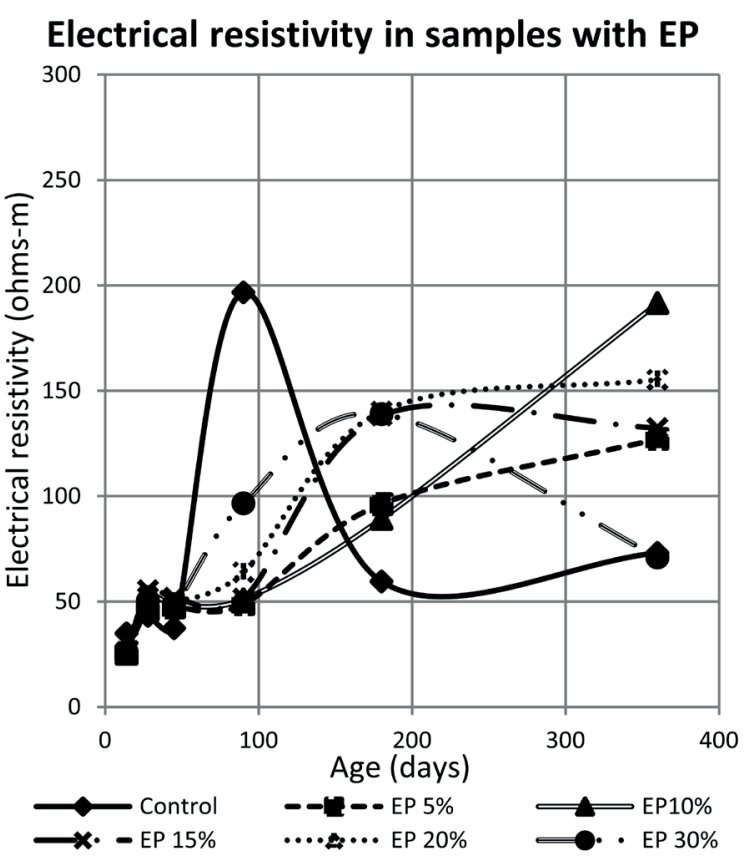

(b)

Fig. 9 a) Electrical resistivity in samples with NP, b) electrical resistivity in samples with EP 


\section{Conclusions}

As for the compressive strength, the best substitution for the NP case was $5 \%$. We can indicate that the substitutions of $15 \%, 20 \%$ and $30 \%$ with EP have a similar tendency between them and it remains horizontal from 150 days, while the substitutions with $5 \%$ and $10 \%$ at the age of 360 days reach the same effort as the control mixture, however, the tendency is upward with respect to time, which indicates that at higher ages will have a better behavior than the control mixture.

As in the compressive strength performance, PAI it is observed that over time the mixture that surpasses the control is $5 \% \mathrm{NP}$ mixture and, in the case of EP mixtures, none surpasses the control mixture. Here the effect of the fluidifier is evident at the early ages, since as age increases IAP decreases, leaving only the pozzolanic effect. The sulfate attack is one of the tests that gives information about the durability of the mixtures under study. The mixtures tested with NP did not reach the fifth cycle, only up to the third cycle, with a better performance the mixture with $5 \%$ of NP. Mixtures with EP and with $15 \%, 20 \%$, and $30 \%$ replacements, which reached the fourth attack cycle. However, the compressive strength is lower than the PN blends. With NP substitutions, $5 \%$ provides better mechanical properties, but with the substitutions of EP the same thing does not happen, even no substitution surpasses the control mixture. Moreover, from the results of electrical resistivity it is concluded that for the NP substitutions $10 \%, 15 \%, 20 \%$ and $30 \%$ a higher resistivity obtained compared with the control mixture, even that the substitution of 5\%. Similar performance with EP substitutions were observed. Then only the percentage of $5 \%$ of NP gives mechanical strength and the rest, apparently, only filled the pores of the mixture remaining as inert material, regardless of test age. Nevertheless, the tendency is ascending with respect to time. Results concluded that the adequate percentages substitution for both products, NP and EP, were those of 5\%, since the results were all acceptable and performed better than the control.

On other hand, cements in Mexico are divided into 6 categories according to the NMX-C-414-ONNCCE (2002), having special formulations to get different performance. However, there is no homologation with the classification established by ASTM C 150 which classifies the cements in 5 types with a specific phase composition (C3S, C2S, C3A, and C4AF) each type. According to the NMX-C-414-ONNCCE, cement types are established by clinker content and no definition of the phases are given, which allows to vary its main composition every day. The slope changes in Figure 3 are attributed to the type of cement used in this work, as mentioned in the manuscript's text, CPC-30R-RS. We have noticed this behavior in the performance of our samples at medium ages, i.e. 45 days, in several laboratory tests from different research projects. But for some reason, this slopes change to positive or negative after 90 days and further, giving a constant tendency with ups and downs vs. aging.

\section{Acknowledgement}

The authors are grateful for the collaboration of the technicians of the Materials Resistance Section of the Laboratory "Ing. Luis Silva Ruelas "of the FIC-UMSNH and would like to thank also, financial support of CIC-UMSNH, PROMEP-SEP and CONACYT.

\section{References}

[1] Arenas-Piedrahita, J. C., Montes-García, P., Mendoza-Rangel, J. M., López Calvo, H. Z., Valdez-Tamez, P. L., Martínez-Reyes, J. "Mechanical and durability properties of mortars prepared with untreated sugarcane bagasse ash and untreated fly ash". Construction and Building Materials, 105, pp. 69-81, 2016. https://doi.org/10.1016/j.conbuildmat.2015.12.047

[2] Ganesan, K., Rajagopal, K., Thangavel, K. "Evaluation of bagasse ash as supplementary cementitious material". Cement \& Concrete Composites, 29(6), pp. 515-524, 2007. https://doi.org/10.1016/j.cemconcomp. 2007.03.001

[3] Arreola, S. M. "Pozzolanic activity of materials (partial substitutes of cement), to improve the durability of mortars for repair and/or construction of concrete structures". Master's thesis, Civil Engineering Faculty, Michoacan University of Saint Nicholas of Hidalgo, August 2013, pp 32-48.

[4] Lanzón, M., García-Ruiz, P. A. "Lightweight cement mortars: advantages and inconveniences of expanded perlite and its influence on fresh and hardened state and durability". Construction and Building Materials, 22(8), pp. 1798-1806, 2008. https://doi.org/10.1016/j.conbuildmat.2007.05.006

[5] Bektas, F., Turanli, L., Monteiro, P. J. M. "Use of perlite powder to suppress the alkali-silica reaction". Cement and Concrete Research, 35(10), pp. 2014-2017, 2005. https://doi.org/10.1016/j.cemconres.2004.10.029

[6] Vargas, J., Halog, A. "Effective carbon emission reductions from using upgraded fly ash in the cement industry". Journal of Cleaner Production, 103, pp. 948-959, 2015. https://doi.org/10.1016/j.jclepro.2015.04.136

[7] Tironi, A., Trezza, M. A., Scian, N., Irassar, E. F. "Assessment of pozzolanic activity of different calcined clays". Cement and Concrete Composites, 37 , pp. 319-327, 2013. https://doi.org/10.1016/j.cemconcomp.2013.01.002

[8] Markiv, T., Sobol, K., Franus, M., Franus, W. "Mechanical and durability properties of concretes incorporating natural zeolite". Archives of Civil and Mechanical Engineering, 16(4), pp. 554-562, 2016. https://doi. org/10.1016/j.acme.2016.03.013

[9] Beddar, M., Meddah, A., Boubakria, M., Haddad, N. "A study of the effects of partial replacement of clinker by limestone in the cement manufacture". Cement Wapno Beton, 3, pp. 185-193, 2014.

[10] Puertas, F., Varga, C., del Mar Alonso, M., Aranzazu Diaz-Batista, M., Lizarraga, S. "New technology for alternative pozzolanic additions for Portland cement from abandoned landfills". Cement Wapno Beton, 2, pp. 88-105, 2015.

[11] Cobirzan, N., Balog, A.-A., Mosonyi, E. "Investigation of the natural pozzolans for usage in cement industry". Procedia Technology, 19, pp. 506-511, 2015. https://doi.org/10.1016/j.protcy.2015.02.072

[12] Erdogan, S. T., Saglık, A. U. "Early-age activation of cement pastes and mortars containing ground perlite as apozzolan". Cement \& Concrete Composites, 38, pp. 29-39, 2013. https://doi.org/10.1016/j.cemconcomp. 2013.03.004

[13] Mladenovic, A., Suput, J. S., Ducman, V., Skapin, A. S. "Alkali-silica reactivity of some frequently used lightweight aggregates". Cement and Concrete Research, 34(10), pp. 1809-1816, 2004. https://doi.org/10.1016/j. cemconres.2004.01.017

[14] Mielenz, R. C., Greene, K. T., Schieltz, N. C. "Natural pozzolans for concrete". Economic Geology, 46(3), pp. 311-328, 1951. https://doi. org/10.2113/gsecongeo.46.3.311 
[15] Erdem, T. K., Meral, Ç., Tokyay, M., Erdogan, T. Y. "Use of perlite as apozzolanic addition in producing blended cements". Cement and Concrete Composites, 29(1), pp. 13-21, 2007. https://doi.org/10.1016/j.cemconcomp. 2006.07.018

[16] Uzal, B., Turanl1, L., Mehta, P. K. "High-volume natural pozzolan concrete for structural applications.". ACI Materials Journal, 104(5), pp. 535-538, 2007.

[17] Turanlı,L.,Uzal,B.,Bektas,F."Effectoflargeamountsofnaturalpozzolan addition on properties of blended cements". Cement and Concrete Research, 35(6), pp. 1106-1111, 2005. https://doi.org/10.1016/j.cemconres. 2004.07.022

[18] Ramezanianpour, A. A., MahmoudMotahari Karein, S., Vosoughi, P., Pilvar, A., Isapour, S., Moodi , F. "Effects of calcined perlite powder as a SCM on the strength and permeability of concrete". Construction and Building Materials, 66, p. 222-228, 2014. https://doi.org/10.1016/j. conbuildmat.2014.05.086

[19] NMX-C-414, Building Industry, Hydraulic Cement, Specifications and Test Methods, 2010.

[20] ASTM C 150,. West Conshohocken, PA: ASTM, 2015.

[21] ASTM C 91-2005;,. West Conshohocken, PA: ASTM, 2005.

[22] ASTM C266,. West Conshohocken, PA: ASTM, 2015.

[23] ASTM C187,. West Conshohocken, PA: ASTM, 2016.

[24] Sanjuan, M. A., Muñoz-Martialay, R. "Influence of the water/cement ratio on the air permeability of concrete". Journal of Materials Science, 31(11), pp. 2829-2832, 1996. https://doi.org/10.1007/BF00355989

[25] Singh, S. B., Munjal, P., Thammishetti, N. "Role of water/cement ratio on strength development of cement mortar". Journal of Building Engineering, 4, pp. 94-100, 2015. https://doi.org/10.1016/j.jobe.2015.09.003

[26] Zhutovsky, S., Kovler, K. "Influence of water to cement ratio on the efficiency of internal curing of high-performance concrete". Construction and Building Materials, 144, pp. 311-316, 2017. https://doi.org/10.1016/j. conbuildmat.2017.03.203

[27] ASTM C1437, Standard Test Method for Flow of Hydraulic Cement Mortar. West Conshohocken, PA: ASTM International, 2015.
[28] ASTM C 494, C 494M, Standard Specification for Chemical Admixtures for Concrete, 2008.

[29] ASTM C109 / C109M, Standard Test Method for Compressive Strength of Hydraulic Cement Mortars (Using 2-in. or [50-mm] Cube Specimens). West Conshohocken, PA,: ASTM International, 2016.

[30] ASTM C311 / C311M, Standard Test Methods for Sampling and Testing Fly Ash or Natural Pozzolans for Use in Portland-Cement Concrete. West Conshohocken, PA: ASTM International, 2016.

[31] ASTM C348 - 14, Standard Test Method for Flexural Strength of Hydraulic-Cement Mortars, PA West Conshohocken, Ed.: ASTM International, 2014.

[32] ASTM C190, Standard Test Method for Tensile Strength of Hydraulic Cement Mortars, 1985.

[33] ASTM C88, Standard Test Method for Soundness of Aggregates by Use of Sodium Sulfate or Magnesium Sulfate. West Conshohocken, PA: ASTM International, 2013.

[34] ASTM C1583 / C1583M, Standard Test Method for Tensile Strength of Concrete Surfaces and the Bond Strength or Tensile Strength of Concrete Repair and Overlay Materials by Direct Tension (Pull-off Method). West Conshohocken, PA,: ASTM International, 2013.

[35] Polder, R. B. "Test methods on site measurement of resistivity of concrete-a RILEM TC 154 technical recommendation". Construction and Building Materials, 15(2-3), pp. 125-131, 2001. https://doi.org/10.1016/ S0950-0618(00)00061-1

[36] Ferreira, M., Liu, G., Nilsson, L., Gjørv, O. E. "Blast-furnace slag cements for concrete durability in marine environment". In: CONSEC 04, fourth international conference on concrete under severe conditions: environment and loading, Seoul, Korea, 2004, pp. 109-116. https://repositorium.sdum. uminho.pt/bitstream/1822/3204/4/RMF(ArtigosCONCEC'04) Blast.pdf

[37] ASTM C 618, "Standard Specification for Coal Fly Ash and Raw or Calcined Natural Pozzolan for Use in Concrete". In: Annual Book of ASTM Standards. West Conshohocken, PA: ASTM, 2003. 